\title{
As senhoras-donas do beco: expressividade e estereótipo de feminino em Cora Coralina
}

\author{
Márcio dos Reis Sales \\ Universidade Cruzeiro do Sul (UNICSUL), São Paulo, São Paulo, Brasil \\ marcio_rsl@yahoo.com.br \\ https://orcid.org/0000-0001-6450-1670
}

DOI: http://dx.doi.org/10.21165/el.v47i3.1956

\begin{abstract}
Resumo
A poetisa contista goiana Cora Coralina é conhecida por suas obras ricas em detalhes do cotidiano do interior brasileiro. Realizando um recorte entre tantas mulheres retratadas em seu bojo literário, com o critério de observar a mulher marginal na sociedade da época, objetivamos neste artigo analisar a construção das imagens das mulheres a partir da expressividade contida nas escolhas lexicais feitas pelo enunciador, e sua interrelação na constituição de estereótipos femininos no conto "Minga, Zóio de Prata". Nesta análise, apoiamo-nos em elementos da Estilística, de acordo com autores como Martins (2012) e Câmara Júnior (1978), em diálogo com a Análise do Discurso de linha francesa no que se refere ao estereótipo, pautando-nos em autores como Amossy e Herschberg Pierrot (2010) e Stangor (2000).
\end{abstract}

Palavras-chave: estilística; escolhas lexicais; estereótipo de feminino; Cora Coralina.

The ladies-owners of the alley: expressiveness and feminine stereotype in Cora Coralina

\begin{abstract}
The poet and writer Cora Coralina is known for her works rich in details of everyday life in the Brazilian interior. Making a cut among the large number of women portrayed in her literary series, with the criterion of observing the marginal woman in the society of the time, in this article, we seek to analyze the construction of women's images from the expressiveness contained in the lexical choices made by the enunciator and its interrelation in the constitution of the feminine stereotypes in the tale "Minga, Zóio de Prata". In this analysis, we based on stylistic elements, according to authors such as Martins (2012) and Câmara Júnior (1978), in dialogue with the Discourse Analysis of the French line about the stereotype, based on authors such as Amossy and Herschberg Pierrot (2010) and Stangor (2000).
\end{abstract}

Keywords: stylistics; lexical choices; feminine stereotype; Cora Coralina.

\section{Introdução}

A obra da poetisa e escritora goiana Cora Coralina tem hoje reconhecimento em todo o país. Segundo Denófrio (2001), Coralina foi a quarta mulher a publicar livro de poemas em Goiás, depois de Leodegária de Jesus (Coroa de lírios, 1906, e Orquídeas, 1928), Regina Lacerda (Pitanga, 1954) e Yêda Schmaltz (Caminhos de mim, 1964). Todavia, pode-se afirmar que foi a primeira em Goiás e uma das primeiras no Brasil a explorar, com amplitude, temáticas que colocavam em evidência personagens marginalizados pela sociedade e, até então, pela Literatura. 
Em suas obras, é possível observar, pelas escolhas linguísticas, as marcas discursivas que compõem os enunciados de narradores e de personagens dessas histórias repletas de indícios de tradição, costumes e estereótipos. Dentro do universo feminino estabelecido nessas narrativas, o objetivo desta pesquisa é analisar a construção das imagens das mulheres a partir da expressividade contida nas escolhas lexicais feitas pelo enunciador, e sua interrelação na constituição de estereótipos femininos no conto "Minga, Zóio de Prata".

Ao nos dedicarmos aos aspectos relacionados à expressividade, ainda que encontremos dificuldade de definir estilo, sua percepção não apresenta o mesmo obstáculo. Riffaterre (1973) define estilo como uma ênfase expressiva, afetiva ou estética que, em colaboração com aquilo que a estrutura linguística informa, realça seu sentido. A ênfase dada, com o uso dos elementos linguísticos, desperta a emoção, o sentimento conjecturado para o enunciado.

Considerando a complexidade de também definir estilo, Câmara Junior (1978, p. 11, tradução nossa ${ }^{1}$ ) adota a conceituação de Pierre Guiraud: “O estilo é o aspecto do enunciado que resulta da escolha dos meios de expressão determinados pela natureza e pelas intenções do sujeito que fala ou escreve".

Adotamos para este trabalho o conceito de Estilística como o estudo da expressividade presente nos enunciados, que pode ser observada pela ênfase expressiva, afetiva ou estética (RIFFATERRE, 1973) em cada situação enunciativa, construída com elementos escolhidos pelo enunciador para atribuir valor ao discurso. Essa expressividade pode, então, ser decorrente de escolhas fonéticas, léxicas, morfológicas, sintáticas. São essas escolhas - especificamente as lexicais neste estudo - que nos permitem observar a imagem do feminino que emerge das seleções realizadas pelo enunciador.

Ao propormos analisar a imagem do feminino, naturalmente esbarramos em imagens historicamente construídas e cristalizadas a respeito da mulher em relação ao corpo, ao comportamento, às relações sociais, entre outros aspectos que funcionam como paradigmas, muitas vezes questionados e fonte de resistências e rupturas ao longo da história das mulheres.

As ações enunciativas, de modo geral, valem-se de imagens convencionais cristalizadas para estabelecer um vínculo de aproximação e reconhecimento entre enunciador e coenunciador, marcadas pela evocação de referentes preexistentes ao ato enunciativo. $\mathrm{O}$ uso dessas imagens estereotipadas contribui para a sustentação do próprio enunciado, ao passo que resgata ideias que o coenunciador compartilha.

Charaudeau e Maingueneau (2004, p. 215), por sua vez, definem o estereótipo como "representação coletiva cristalizada", construída na interação entre os interlocutores. Stangor (2000) afirma que os estereótipos podem ser pensados como as características que estão mentalmente associadas a um rótulo de categoria social constituído a longo prazo. Complementando, Amossy (2010, p. 113, tradução nossa ${ }^{2}$ ) defende que o pré-construído vem de uma concepção "o sujeito que não é um sujeito

\footnotetext{
1 "El estilo es el aspecto de lo enunciado que resulta de una elección de los médios de la expressión determinada por la natureza y las intenciones de sujeto que abla o escribre".

2 "del sujeto que no es sujeto idealista intencional de la pragmática linguística, sino un sujeto prisionero de un linguaje donde lo preafirmado gobierna lo afirmado".
} 
idealista intencional da linguística pragmática, mas um sujeito aprisionado em uma língua onde o já-dito governa o enunciado". O estereótipo, assim, resgata discursos e juízos já realizados, cuja origem já está apagada, os quais direcionam o enunciado de acordo com a imagem cristalizada.

Ao tratar da imagem da mulher construída pelas escolhas linguísticas do enunciador no corpus selecionado, observamos a presença desses "já-ditos", que, repetidamente usados ao longo do tempo, tornaram-se "cristalizados", compondo um conjunto de ideias que constituem o universo feminino. Essas ideias, funcionando como estereótipos, aparecem ora reproduzidas, ora atualizadas e transformadas.

\section{Revelando o feminino}

No conto "Minga, Zóio de Prata", de Cora Coralina (2006), encontramos um ambiente que envolve a imagem da mulher de maneira peculiar. As personagens presentes na narrativa são conhecidas por serem prostitutas, ofício que assumem como meio de sobrevivência. $\mathrm{O}$ ambiente em que se estabelecem não é um qualquer, mas o beco, lugar daqueles que não têm espaço na cidade e, por extensão, na sociedade tradicional. Entretanto, a mulher marginalizada assume, nesse contexto, um papel de sujeito de sua história, ocupando o lugar de autoridade, a ponto de tomar atitudes enérgicas para manter a posição de domínio conquistado, conforme pode ser observado na leitura e análise que segue.

Essa narrativa recebe o nome da protagonista, uma das duas prostitutas de um beco da cidade. Minga e Dondoca são irmãs que atendem os homens em casa.

(1) Eram elas senhoras-donas, ali no beco do Calabrote.

O primeiro enunciado refere-se anaforicamente às duas prostitutas sobre as quais o enunciador narra a história. O emprego do pronome elas revela que Minga não é a única mulher da narrativa. Ambas, Minga e Dondoca, são apresentadas pelo enunciador como senhoras-donas do beco. A imagem que se relaciona a essa escolha lexical nos direciona a mulheres respeitadas e dotadas de autoridade, com certo prestígio, sobressaindo-se, numa espécie de hierarquia, em relação às demais prostitutas.

Lembrando Possenti (2001), as escolhas e exclusões dos recursos expressivos, estabelecendo relações entre enunciador e coenunciador, são capazes de revelar a presença da subjetividade na linguagem. Temos assim a marca da presença subjetiva do enunciador, a qual pode ser percebida pelas escolhas lexicais que revelam o estilo e as imagens que o enunciador compartilha.

O conto é narrado em terceira pessoa, traço que instaura o enunciador como observador dos fatos. Assim, o enunciador fala de Minga e Dondoca pela perspectiva de quem assiste os acontecimentos e os transmite a partir de seu ponto de vista. Olhar este que está deflagrado pela escolha do advérbio pronominal ali, que marca sua posição enunciativa.

O posicionamento das personagens no espaço em que realiza a história é fundamental para mostrar quem são e qual posição ocupam em relação à cidade. 
O espaço é como o ar que se respira. Sabemos que sem ar morremos, mas não vemos nem sentimos atmosfera que nos nutre de força e vida. Para sentir o ar é preciso situarse, meter-se numa certa perspectiva [...]. Do mesmo modo, para "ver" e "sentir" o espaço, torna-se necessário situar-se. (DAMATTA, 1985, p. 25).

A localização do beco é capaz de trazer à tona a perspectiva de observação do enunciador, bem como o "ar" que as personagens respiram, que não é o mesmo se estivessem no centro da cidade. As pessoas que nele residem e circulam possuem suas peculiaridades em relação aos demais espaços. Britto traz uma importante contribuição para compreender o que os becos goianos representam nessa sociedade e sua relação com os espaços privilegiados da cidade. $\mathrm{O}$ espaço do beco se contrapõe ao do largo. Enquanto os largos estão ligados pelas ruas principais, onde vivem as famílias da sociedade reconhecida, os becos são construções feitas para facilitar o acesso às ruas, geralmente surgindo na confluência dos quintais e funcionando como expurgo de tudo o que a sociedade desejava evitar.

Ao desvendar a representação do beco nessa sociedade, inevitavelmente constata-se que as personagens ocupam um espaço físico e socialmente rejeitado, configurando-se um ambiente de segregação. A cidade de Goiás de meados do século XX era constituída por uma sociedade em que o mundo considerado oficial era regido pelas práticas conservadoras, das famílias que residiam nos largos e ruas principais (BRITTO, 2006). Essa sociedade elegeu os becos como locais dos segregados.

Com a separação desses espaços, aqueles que habitam as ruas principais se consideravam em posição diferente, superior aos moradores dos becos. O beco constitui-se, assim, em um local de estigmas: pobreza, vícios, prostituição, e por isso evitado pela população, que o utiliza apenas como passagem. Ao estabelecer essa ligação da mulher com o espaço e o que este representa para a sociedade, a imagem da mulher prostituta do beco firma-se no estereótipo de marginalização da prostituta, que o contexto do conto em análise destaca a posição das personagens dentro desse espaço, ou seja, a diferença de status dentro e fora do beco.

Essa marginalização não é para banir, mas colocar as prostitutas num espaço no qual podem exercer um papel na sociedade sem que estejam no centro da cidade, local reservado para aquilo que é considerado oficial, direito, público (DAMATTA, 1985).

Relegadas hipocritamente à margem da sociedade, as prostitutas desempenham papel importante. A função delas, no entanto, é contribuir para a ordem social, mas precisam estar em algum lugar para que a cidade se mantenha como lugar elitizado. $\mathrm{O}$ cristianismo despreza-as, mas as aceita como um mal necessário, como afirma Santo Agostinho: "Suprimi as prostitutas, diz Santo Agostinho, e perturbareis a sociedade com a libertinagem" (SANTO AGOSTINHO apud BEAUVOIR, 1967, p. 127). E posteriormente Santo Tomás - ou o teólogo que assinou com esse nome o livro IV do De regimine principium — declara:

Eliminai as mulheres públicas do seio da sociedade, e a devassidão a perturbará com desordens de toda espécie. São as prostitutas, numa cidade, a mesma coisa que uma cloaca num palácio; suprimi a cloaca e o palácio tornar-se-á um lugar sujo e infecto. (SANTO TOMÁS apud BEAUVOIR, 1967, p. 127).

Assim, observamos uma relação entre o espaço e o ofício de meretriz na constituição do estereótipo da mulher. Ser prostituta no beco configura-se como um 
modo de ser, diferente daquela que exerce a mesma prática no centro. Conforme Gaspar (1985), o grau de estigmatização dessas mulheres depende de sua posição no grupo social, uma vez que aquelas consideradas uma categoria inferior da hierarquia social estão mais sujeitas a uma rotulação calcada num estereótipo retirado das camadas mais pobres da sociedade. A relação com a pobreza gera a ideia de que a prostituta de baixa renda terá o maior número de parceiros sexuais. Estar no beco revela essa condição social das irmãs e as liga ao estereótipo da prostituta pobre, promíscua e contaminadora.

Entretanto, aqueles que estão dentro do beco, ou circulam por ele, têm outra visão sobre Zóio de Prata e Dondoca. No que se refere às personagens propriamente ditas e à escolha lexical para apresentá-las, a palavra senhora, entre os seus significados, pode referir-se à mulher que exerce poder, dominação, influência; aquela que possui algo como proprietária, bem como pode ser usado também como forma de tratamento às mulheres nobres e distintas (HOUAISS, 2001). Para dona encontramos a definição de "título concedido às mulheres das famílias reais de Portugal" (HOUAISS, 2001), estendendo-se também àquelas dotadas de algum título de superioridade ou respeito, como as casadas, viúvas, religiosas, idosas etc.

A composição senhoras-donas confere às irmãs o status de superioridade. Isso acontece ao unir a significação de autoridade e propriedade que os dois vocábulos, numa composição de justaposição, possuem ao se complementar. $\mathrm{O}$ enunciador vale-se dessa construção para atribuir às irmãs o controle que exercem no beco.

As personagens, como meretrizes numa sociedade tradicional, estão completamente fora de um estilo de vida que lhes atribui tais qualidades. Contraditoriamente, sendo ambas prostitutas do beco, são chamadas senhoras-donas, destacando-se da expressão mulher-dama, pela qual eram tratadas as prostitutas. Assim, um tratamento substitui o outro, sugerindo um jogo de palavras. O primeiro, em analogia ao segundo, recupera o sentido de nobreza para elevar o grau das meretrizes, atribuindo-lhes outro status, o de autoridades dentro do beco.

No entanto, essa autoridade não é exercida em toda a cidade, mas tem seu espaço demarcado. O emprego do vocábulo beco revela essa limitação espacial e geográfica, uma vez que se refere a uma rua estreita e curta geralmente fechada num extremo (FERREIRA, 2010). Contudo, essa restrição do domínio das irmãs é reforçada pelo emprego do advérbio ali, que, funcionando na língua fundamentalmente como um modificador do verbo (CUNHA; CINTRA, 2001), aponta para a validade do poder exercido pelas irmãs apenas em um lugar específico. Assim, fora do beco, Minga e Dondoca não exercem autoridade alguma.

Essa separação dos espaços não acontece apenas geograficamente entre as ruas estreitas do beco e os largos de forma física.

[...] o espaço é demarcado quando alguém estabelece fronteiras, separando um pedaço de chão do outro, mas nada pode ser tão simples assim, porque é preciso explicar de que modo as separações são feitas e como são legitimadas e aceitas pela comunidade como um todo. (DAMATTA, 1985, p. 28).

Assim, essa delimitação extrapola o físico, uma vez que se configura como uma invenção social. Os moradores dos becos não exercem o mesmo papel fora dele; do mesmo modo as prostitutas, Minga e Dondoca, não podem exercer a autoridade que têm no beco em outros espaços senão naquele que a sociedade as restringe. Esse 
aprisionamento gerado pelas fronteiras sociais reafirma a marginalização da mulher que se prostitui.

Observando a construção fonológica da expressão ali no beco, é possível perceber a presença das vogais /i/ e /e/ que reforçam a ideia de estreitamento presente nos vocábulos. Conforme Martins (2012, p. 51), "o estreitamento do conduto bucal na produção do [i] se coaduna à expressão de pequenez, estreiteza", o mesmo acontece com o fechamento produzido pela vogal /e/. Ambos os vocábulos colaboram de maneira expressiva, coadunando a imagem da limitação espacial do domínio das irmãs.

Ademais, o emprego da preposição em + o na expressão no beco também evidencia a limitação da autoridade das irmãs. Segundo Cunha e Cintra (2001), a preposição em, quando marcada pela ausência de movimento, indica "dentro dos limites de". Assim, a preposição relaciona as palavras baseada na ideia central de restrição. É, então, somente no beco que Minga e Dondoca exercem poder.

(2) Quem transitasse pelo beco, tivesse cuidado... Passasse quieto e bonzinho. Não se engraçasse nem fizesse cara de pouco. [...] Macho, porém, que não se fizesse de besta... Eram donas e autoridades no beco. $\mathrm{O}$ beco era delas. E tinham prestígio.

Todo esse reconhecimento opõe-se ao desprestígio que essas mulheres têm fora dos espaços demarcados socialmente para a prostituição, uma vez que na cidade não há espaço para elas, sofrendo a aversão das famílias tradicionais. A mulher, que tem como estereótipo do início do século XX uma figura submissa ao homem e que fora do beco é sujeita à tradição patriarcal, dentro do beco subverte as regras e submete às suas próprias regras aqueles que entram em seu território. E quem entra nesse outro lado da cidade precisa sujeitar-se às regras ditadas pelos seus líderes, como acontece com Minga e Dondoca.

A imagem da autoridade das irmãs emerge como mostra da luta da mulher no século XX. Havia de fato uma tensão entre os comportamentos de submissão e o desejo de libertação feminina.

Não faltavam vozes nesse começo de século para entoar publicamente o brado feminino de inconformismo, tocado pela imagem depreciativa com que as mulheres eram vistas e se viam e, sobretudo, angustiado com a representação social que lhes restringia tanto as atividades econômicas quanto as políticas (MALUF; MOTT, 1998). O enunciador, ao apresentar o comportamento de Minga e Dondoca, aponta para esse brado por libertação que ambas constroem no beco, invertendo a relação com o masculino.

Nesse sentido, o enunciador revela uma visão alternativa da realidade ao tomar um enredo no qual se invertem as relações entre personagens, entre homens e mulheres, lançando o foco narrativo sobre algo novo. Essa visão alternativa é desenvolvida, no enredo do conto, ao oferecer uma perspectiva incomum, quando mulheres são capazes de exercer o poder numa sociedade controlada pelo homem. A mulher adentra outro universo que até então não conhecia, a dominação e supremacia, ainda que num contexto limitado às pequenas ruas do beco. A imagem constituída de Minga e Dondoca segue esse viés da subversão e domínio, necessário para a subsistência das irmãs.

O estereótipo de mulher como submissa, que se ampara na figura masculina para sua subsistência, não encontra nas Cômodas uma atualização que reforce essa imagem 
(LYSARDO-DIAS, 2007), ao contrário, a imagem que se atualiza e reforça é a da mulher resistente aos padrões e à supremacia masculina, das quais se encontram "protótipos 3 " espalhados ao longo da História.

A divisão dos limites do beco e os diferentes agentes que exercem força e autoridade dentro e fora dele também são capazes de demarcar as classes sociais: de um lado, nas ruas principais, a classe dominante e do outro, a classe dos dominados, confinados às estreitas ruas do beco. No entanto, ainda que os moradores dos largos representem a classe dominante, esse domínio não entra onde as autoridades são as Cômodas.

As mulheres que possuíam algum prestígio abriam ou integravam casas de prostituição em locais mais afastados e eram financiadas por seus clientes, na maioria políticos, policiais e membros das famílias então dominantes; já para as destituídas de proteção restavam os becos (BRITTO, 2006).

As duas irmãs não possuem prestígio externo suficiente para manter uma casa em locais mais afastados, por isso refugiam-se no beco. Conforme apresenta Britto (2006), mesmo as mulheres que não se instalavam nos becos, ao buscar lugares afastados, mostram que eram relegadas dos espaços centrais da cidade.

A relação que Minga e Dondoca têm com a cidade é apenas com os homens que as procuravam. E por eles, suas funções são bem claras e conhecidas por todos.

$$
\text { Também eram conhecidas por As Cômodas, na roda da macheza. }
$$

Entre os homens, Minga e Dondoca têm um codinome peculiar. Essa escolha nos remete ao significado de cômodas, como feminino de cômodo no sentido de conforto, de comodidade (HOUAISS, 2001). Ambas as irmãs gozam de uma posição confortável no beco, são consideradas donas desse espaço e nele ditam as regras e são exemplos para outras prostitutas. Além disso, Dondoca não precisa pleitear clientes, pois tem o seu homem fixo.

Por outro lado, a palavra cômodas também se refere ao significado de um móvel como uma espécie de mesa com gavetas, remete-nos à representação dessas mulheres como objetos, ou protótipos de feminino que servem apenas para o uso daqueles que as procuram para o serviço sexual. Temos então um processo de coisificação da mulher. Esse processo de degradação da mulher ao nível de coisa acontece, segundo Beauvoir (1970), devido aos diversos percalços da prostituição. Traz à mulher a opressão sexual e econômica, bem como a arbitrariedade da polícia, a humilhante fiscalização médica, os caprichos dos fregueses, a facilidade de contrair doenças, a miséria, que tornam as prostitutas párias da sociedade.

A imagem de objeto sustenta-se na função claramente definida que exercem e revela-se na relação mantida com os homens, estritamente sexual, sem maiores delongas para o envolvimento afetivo.

\footnotetext{
${ }^{3}$ Adotamos a noção de protótipo como "o menor exemplar comumente associado a uma categoria. É de certa forma uma subcategoria, que representa de uma maneira exemplar uma categoria. Dizemos que um pardal é um protótipo da categoria pássaro. [...] Em outras palavras, o protótipo se define como exemplar que resume as propriedades típicas ou sobressalentes da categoria. De acordo com isso, pode haver muitos protótipos de uma mesma categoria.” (KLEIBER, apud AMOSSY; PIERROT, 2010, p. 99).
} 
Dondoca, no entanto, possui seu cliente fixo, Izé da Bina, que também é apresentado pelo enunciador como amigo em:

(4) Tinha entrado na peia do amigo — o Izé da Bina — à-toa, ruindade de pingado ordinário.

A escolha lexical amigo deflagra que a relação de Izé com Dondoca não é pública. Ademais, o nome de Izé é atrelado ao complemento da Bina. Essa combinação nos remete à ideia de pertencimento próprio da preposição de, capaz de sugerir que Izé tem alguma relação com outra mulher, provavelmente sua esposa.

Minga, ao contrário da irmã, não tem seu cliente fixo. No entanto, observamos que mantém uma posição estável com sua postura de durona. Nesse sentido, as duas irmãs têm tanto uma ocupação quanto um ofício estáveis.

(5) E quem fosse de entrar, empurrasse a porta de dentro, com fala curta e dinheiro pronto.

Tal relação, objetiva e bem delimitada, assemelha-se ao comportamento machofêmea, como lembrado na escolha lexical para se referir aos homens que as procuravam.

A recuperação do estereótipo da relação animal, macho-fêmea, traz o ideário do coito sem envolvimento afetivo voltado apenas à reprodução. Nesse caso, é descartada a ideia de reprodução, pois o envolvimento acontece apenas para saciar o desejo sexual, revelando uma relação visceral também vista como instintiva e análoga aos seres irracionais.

(6) Macho, porém, não se fizesse de besta.

Ao mesmo tempo em que o enunciador compara a relação homem e mulher à de animais, ele parece fazer um jogo com as ideias de macho e besta. Embora realize a analogia do homem ao macho, esse não devia se comportar como besta, palavra que recupera a ideia compartilhada do bestial, daquele que finge desconhecimento (FERREIRA, 2010), para deixar de pagar pelo programa.

Inevitavelmente, a imagem feminina constitui-se em relação à figura masculina. Na sociedade patriarcal, o homem é o parâmetro e o detentor do poder. Ele é o UM e a mulher se configura no OUTRO, que só existe em relação ao primeiro. Ainda que as irmãs exerçam autoridade no beco, elas não se isolam do ambiente em que esse beco está estabelecido. Por isso, essa relação sustenta-se na concepção de que:

O homem é pensável sem a mulher. Ela não, sem o homem. Ela não é senão o que o homem decide que seja; daí dizer-se o "sexo" para dizer que ela se apresenta diante do macho como um ser sexuado: para ele, a fêmea é sexo, logo ela o é absolutamente. A mulher determina-se e diferencia-se em relação ao homem e não este em relação a ela; a fêmea é o inessencial perante o essencial. O homem é o Sujeito, o Absoluto; ela é o Outro. (BEAUVOUIR, 1967, p. 10).

Se o homem busca a mulher meretriz para o sexo, a advertência aos homens em "Macho, porém, não se fizesse de besta" remete à tentativa de o homem sobressair-se no território das Cômodas, onde elas detêm o poder e lutam para mantê-lo a qualquer custo.

A reputação das irmãs também é responsável pela autoridade de que gozam no beco. Se por um lado se sustenta essa proximidade ao animal, por outro nos atributos 
usados pelo enunciador para constituir a imagem de Minga e Dondoca, observamos o apontamento do comportamento das duas personagens que são apresentadas com atitudes que lhes atribuíam certa diferença em relação às demais prostitutas.

(7) Escândalo de mulher-dama não dava, nunca deu; também nunca foram levadas, como tantas, para capinar na frente da cadeia.

A combinação do advérbio nunca com a conjunção como parece contribuir para a exclusão de Minga e Dondoca do meio das demais prostitutas com comportamentos escandalosos, modalizando os verbos a que se referem. Assim, o advérbio de negação nunca, empregado duas vezes, além do advérbio não, contribuem para a construção de uma imagem que as diferencia das tantas outras que agem de maneira que lhes implica uma punição pública. Por sua vez, a conjunção comparativa como junto com o advérbio nunca não só as contrasta com outras prostitutas como enfatiza a superioridade de conduta das duas sobre as demais meretrizes. Nota-se, nessa construção, a oposição estabelecida em relação ao estereótipo de mulher-dama resgatado pelo enunciador que, pela conjunção como, revela essa imagem da mulher inclinada ao escândalo e à confusão, merecedora de uma punição exemplar para não ser tida como modelo para as demais. Mais uma vez, o enunciador coloca as irmãs em outro patamar, que atualiza o estereótipo de meretriz, por um viés não pejorativo. Em outras palavras, o enunciador apresenta outro protótipo de meretriz, a comportada e exemplar, que justifica sua condição de autoridade, legitimada por seu comportamento exemplar dentro do beco.

Minga e Dondoca têm, então, um comportamento considerado adequado no que se refere ao modo de agir no espaço público. Conforme Damatta (1985, p. 41), "o comportamento esperado não é uma conduta única nos três espaços [casa, rua, outro mundo], mas um comportamento diferenciado de acordo com o ponto de vista de cada uma dessas esferas de significação". Embora o público seja visto como o movimentado, propício aos conflitos, desgraças, há comportamentos que são esperados de acordo com a ordem social. As irmãs mantinham a ordem dentro do beco, transformando-o em um espaço diferente daquele presente no ideário da sociedade.

Embora o beco fosse considerado um lugar dos segregados, o modo como as irmãs o dominam faz dele um ambiente diferenciado. $\mathrm{O}$ modo de ser de Minga e Dondoca as torna discretas, tanto no lidar com seus clientes, quanto no comportamento no beco, a ponto de famílias poderem passar por ele e não verem nada escandaloso para os costumes tradicionais.

(8) Família de respeito podia passar a toda hora, não via nada.

Segundo Britto (2006), aqueles que fugiam do comportamento restritivo eram sujeitos à punição que implicava numa "relação servil de docilidade e utilidade". Essas punições públicas, como capinar na frente da cadeia, serviam para manter a hierarquia social e de comando sob as quais essas mulheres e outros infratores estavam. A imagem construída pelo enunciador mostra que o reconhecimento como senhoras-donas no beco, também passa pelo comportamento exemplar das irmãs. Esse status, portanto, é reforçado pela imagem do beco como ambiente capaz de receber a passagem de famílias de respeito, que também traz a ideia de urbanidade, uma vez que no estereótipo de "família de respeito" entram os lugares pelos quais podem transitar sem pôr em questionamento a retidão daqueles que passavam pelo beco. 
Nesse espaço, as duas meretrizes vivem discretas e comportadas. Porém, Minga assume atitudes agressivas e enérgicas, sem reproduzir ações consideradas dentro do bojo de estereótipo feminino, como a feminilidade e a sutileza, para adotar comportamentos capazes de garantir o sustento e a estabilidade. Nesse sentido, elas criam um universo longe daquele vivido pelas mulheres comuns de seu tempo, como que traindo a construção social do feminino em prol da manutenção de seu status e de sua sobrevivência.

Em relação à imagem física das personagens, lembra Garcia (2006) que, numa descrição, o propósito é destacar o objeto, pessoa ou personagem por meio de seus traços típicos de modo que se possa distingui-lo de outros semelhantes, sendo inútil descrever algo se nada fosse apresentado de característico. A imagem constituída pela descrição de Zóio de Prata ressalta os traços do corpo masculino.

(9) Tinha mesmo um bugalho branco, saltado, e era vesga do outro. Espinhenta, de cabelo sarará, mulatona encorpada, de bacia estreita, peito masculino, de mamilos duros, musculosa; servindo bem no oficio, de fala curta, braço forte, mãos grandes.

A descrição objetiva que o enunciador faz da personagem colabora para criar uma imagem próxima da figura masculina por meio de seus traços predominantes. Dessa descrição observamos a explicação da expressão zóio de prata.

O vocábulo bugalho, que se refere ao globo ocular, assume um sentido depreciativo que ressalta o prejuízo estético de Minga. O olho grande e saltado lhe rende o codinome de zóio de prata, expressão criada a partir de processo morfofonêmico de composição por aglutinação e metaplasmos ${ }^{4}$, passando de "olhos de prata" para "zóio de prata", próprio da fala de pessoas com linguagem rudimentar.

A escolha lexical encorpada não se refere aos contornos do corpo feminino, mas ao volume do peito masculino, aos mamilos duros, à forma musculosa do corpo de Minga, com o braço forte e as mãos grandes. Essas escolhas lexicais que constroem a imagem física dessa mulher nos remetem mais ao corpo masculino, dotado de músculos, do que ao volume do corpo feminino. Ao mesmo tempo em que a descreve como encorpada, o enunciador emprega bacia estreita, o que colabora com a ideia do corpo magro e musculoso do homem.

Ao descrever os seios de Minga com o emprego de peito masculino, o enunciador recupera o estereótipo do corpo do homem, forte, enrijecido, com volume somente devido aos músculos. Esse emprego opõe-se ao estereótipo do corpo feminino, constituído pelos seios salientes e menos enrijecidos que o masculino. Assim, o enunciador atualiza a imagem da mulher, que na narrativa é musculosa, com traços mais rudimentares, constituindo uma composição corporal diferente da imagem cristalizada do feminino.

$\mathrm{Na}$ descrição, o cabelo sarará nos remete à imagem do cabelo crespo de cor alourada ou arruivada característico de certos mulatos (FERREIRA, 2010), além de estar vinculado à ideia de despenteado, contribuindo para ressaltar o prejuízo estético da personagem.

\footnotetext{
${ }^{4}$ Sonorização /s/ > /z/: os olhos > ozolhos; Aférese (queda) /o/: ozolhos $>$ zolhos; Vocalização $/ \lambda />/ \gamma /$ : zolhos > zoios; Apócope (queda) /s/: zoios > zoio.
} 
Das 14 expressões empregadas pelo enunciador para descrever Minga, observamos seis delas que a aproximam do corpo masculino (bacia estreita, peito masculino, mamilos duros, musculosa, braço forte, mãos grandes) e outras cinco que a descrevem de forma depreciativa (bugalho, saltado, vesga, espinhenta, cabelo sarará). Essa ligação com o corpo masculino é reflexo de uma construção social pautada nos estereótipos de corpo masculino e feminino, e, no confronto entre essas imagens, revelase como Minga é diferente do estereótipo do corpo feminino.

O corpo e seus movimentos, matrizes de universais que estão submetidos a um trabalho de construção social, não são nem completamente determinados em sua significação, sobretudo sexual, nem totalmente indeterminados, de modo que $\mathrm{o}$ simbolismo que lhes é atribuído é, ao mesmo tempo, convencional e "motivado", e assim percebido como quase natural (BOURDIEU, 2003).

De fato, a construção social dos corpos remete alguns traços a um ou a outro sexo. Essa atribuição tem ligação com o papel que cada um exerce no mundo, revelando as dicotomias forte/fraco, superior/inferior, dominador/dominado etc.. Essa aproximação da imagem do feminino ao masculino serve para evidenciar sua virilidade e força, ainda vinculadas ao homem. Como destaca Beauvoir (1967), a divisão dos sexos é um dado biológico apenas; a inferiorização da mulher decorre de uma construção social e, portanto, é mutável.

Todo o corpo masculinizado de Minga lhe é útil para "servir bem no ofício", no trabalho do dia a dia que lhe exige força e agilidade para as tarefas domésticas. $\mathrm{O}$ único traço psicológico de Minga que o enunciador revela ao descrevê-la é o "de fala curta", ou seja, a personagem é objetiva, sucinta e sem muitas delongas, conforme explicitado pelo léxico.

Minga é, então, descrita como durona, capaz de enfrentar de igual para igual aquele que ousasse sair sem pagar pelo programa. No vocábulo durona, o sufixo - ona atribui o aumentativo às características de força e braveza do radical, coadunando-se com a ideia de mulher grande e forte atribuída a Minga. O sufixo adquire um valor expressivo ao harmonizar com a descrição física de Minga, Zóio de Prata, como mulatona encorpada também no aumentativo, enfatizando seu aspecto corpulento. Entretanto, a descrição física de Minga não condiz com a imagem de uma mulher delicada e carinhosa que precisa agradar os homens para atraí-los para o programa.

A descrição de Minga está constituída em torno da virilidade que lhe dá um diferencial, tanto para o ofício quanto para o trato com os homens com quem se relaciona. Esse aspecto viril constitui-se em relação à imagem do masculino. Não é por acaso que as expressões usadas (peito masculino, mamilos duros, musculosa) são empregadas para dar atributos de força à mulher. $\mathrm{O}$ homem é a referência. Aristóteles já afirmava que a mulher é mulher por falta de virilidade (BEAUVOIR, 1967), ela se constitui pela ausência de elementos que o homem possui. Essa, segundo Aristóteles, era uma condição que o sexo feminino devia suportar sem poder modificá-lo. A mulher é, então, considerada como sofredora de certa deficiência natural.

Por outro lado, a irmã é descrita de maneira oposta à Minga. O fato de ser chamada de "Dondoca" mostra uma mulher que não precisa fazer muito esforço na vida (HOUAISS, 2001), uma vez que já possui seu cliente fixo, a quem servia com pontualidade. 
Dondoca parece ser a mais feminina das duas. Suas percepções, pelo fato de gozar de uma situação mais estável, parecem estar voltadas, como qualquer dondoca, para coisas mais secundárias ou fúteis. Zóio de Prata é a provedora das primeiras necessidades das duas, responsável por levar comida para casa, trazendo o frango que comprou no mercado, enquanto a irmã permanece em casa.

(10) voltava ela do mercado com um frango na mão...

Podemos, então, considerar que a imagem constituída de Dondoca esteja mais próxima do estereótipo de feminilidade, enquanto Zóio de Prata, de acordo com as características apresentadas em sua descrição, foge do ideário de mulher delicada e submissa, quando se trata da imagem de uma prostituta, uma vez que seus traços são másculos e pouco atrativos para os homens.

O comportamento de Dondoca diante de Izé da Bina parece revelar um envolvimento que excede o de prostituta - cliente.

(11) deu de cara com a irmã chorando, de cara amassada e beiço partido. Tinha entrado na peia do amigo — o Izé da Bina — à-toa, ruindade de pingado ordinário.

Embora a fama das Cômodas seja de autoridades do beco, com Izé da Bina a reação de Dondoca é completamente diferente, a ponto de ela apanhar do seu cliente. "Entrar na peia", metaforicamente, refere-se à violência física ao ser agredida com o instrumento de açoite próprio dos peões, usado para chicotear os animais.

Nessa relação parece haver certa submissão de Dondoca a Izé da Bina, semelhante à mulher casada submissa ao marido que, numa situação de conflito, não revidaria a agressão do companheiro. Dondoca é sempre disponível a Izé da Bina e age com ele diferentemente dos demais. Nesse relacionamento, há indícios de algo que vai além do material para que a personagem seja capaz de tolerar a agressão recebida. Minga toma as dores de Dondoca que não resolve a situação, apenas chora pelo ocorrido. Tal comportamento de Dondoca revela certo cuidado para não criar mais atrito com Izé da Bina, uma vez que quem resolve a situação retribuindo a agressão é a irmã. Dondoca evita, assim, despertar o repúdio do seu homem. Essa suposta estratégia adotada por Minga a exclui da responsabilidade pela resposta à agressão dada pela irmã. Mesmo depois de vingada, ela não responderia pela ação da outra, podendo voltar ao seu homem sem possíveis ressentimentos dele para com ela.

A personagem Zóio de Prata, ao buscar vingar-se do agressor assume a atitude protetora semelhante à do patriarca da casa, ou do cafetão que defende a prostitua contra os maus tratos e o inadimplente (BEAUVOIR, 1970), quando vê sua irmã ultrajada pelo cliente.

(12) Dei'stá - disse ela - sai fora e deixa por minha conta. Óia, vai depená esse frango pra nóis na casa da vizinha e só entra quando eu chamá...

O próprio modo como se vinga pela irmã faz a personagem aproximar-se da figura masculina, uma vez que ela se coloca de igual para igual para agredir fisicamente o ofensor de sua irmã, renegando a feminilidade e delicadeza atribuídas socialmente à mulher. 
Entretanto, ao descrever Minga com tais características, o enunciador revela a constituição de um protótipo de mulher que extrapola o estereótipo de feminino calcado na ausência de virilidade.

(13) Atirou-se no mulato com vontade e foi porretada de direita e canhota. Bateu com sustância, sovou com fôlego, quebrou as carnes, moeu bem moído. No fim, jogou fora o cacete e entrou de corpo. Numa boa sobarbada deu com o crioulo no chão. Sentou em cima e esmurrou à vontade. Quebrou as ventas, partiu dois dentes, entrou no olho... xingou nomes...

A vingança de Zóio de Prata acontece de forma progressiva. Ela bate, sova, quebra, mói, assim progride e cresce sobre o homem que parece não ter nenhuma oportunidade de reação diante da força e agilidade da personagem. Os verbos empregados são dispostos de maneira a formar uma gradação que retrata a tensão da luta, que se inicia com o verbo sovar, passando por bater, que é mais que sovar, seguindo quebrar e moer que são mais agressivos do que as ações anteriores, caminhando em direção a um clímax que se revela no final da briga. A ordem das escolhas lexicais passa a expressar quão violenta a vingança de Zóio de Prata se torna, a ponto de rendê-lo, batendo-lhe por meio de uma surra violenta. Depois de largar o cacete, Zóio de Prata ainda quebra as ventas e parte os dentes, de modo a superar a força de Izé da Bina com facilidade suficiente para bater em seu adversário com as próprias mãos.

E, mais do que a agressão física, a personagem finaliza sua vingança de modo a legitimar sua supremacia sobre os homens e sua autoridade no beco.

(14) ...xingou nomes... desses de ouvindo dizer o Antônio Meiaquarta, tipo de rua, rei dos bocas-sujas da cidade: eu sei dois contos e quinhentos de nomes indecentes...

Zóio de Prata é colocada em contraste com o rei dos bocas-sujas da cidade. A comparação aproxima e iguala a mulher ao comportamento do homem tido como aquele que profere os piores palavrões.

Além de resolver a situação, Zóio de Prata extrapola a agressão física e marca sua autoridade no beco:

(15) Depois de ver o cabra mole, estirado, fungando, Zóio de Prata assungou a saia, abriu as pernas e mijou na cara de Izé da Bina.

Estava vingada a Dondoca e consolidada da fama das Cômodas.

O fato de urinar em Izé da Bina tem a função de consolidar a imagem que ambas já construíram em seu território. Ferreira (2010) traz os significados para consolidar: tornar sólido, seguro, estável. A violência de Zé da Bina contra Dondoca desestabilizou a autoridade das irmãs no beco. Minga, para não correr o risco de sofrer a desmoralização e perder a posição conquistada, vale-se da sua vingança para mostrar quem manda no beco. Urinar na cara do derrotado marca a vitória dessa mulher que resiste aos caprichos dos fregueses. 


\section{Considerações finais}

Considerando o contexto em que estão inseridas, Minga e Dondoca, ao buscar manter a posição de vida que escolheram, assumem um papel de sujeito de suas vidas, assim como as consequências de serem prostitutas numa sociedade tradicional.

O enunciador, do ponto de vista da expressividade das escolhas lexicais, constrói a imagem das duas irmãs de maneiras distintas. Dondoca, a quem pouco se refere, é traçada à imagem da mulher marginalizada pela prostituição, que vive uma situação de estabilidade pelo fato de ter seu cliente fixo e que ao mesmo tempo assume uma posição de submissão e de dependência de Minga para defendê-la em situações conflituosas.

Por outro lado, Minga é constituída como a mulher que não corresponde ao padrão de feminilidade e se assemelha à imagem masculina, seja pelo corpo musculoso e masculinizado, seja pelas atitudes de proteção para com a irmã e pelo domínio de seu território, o beco. A descrição do corpo de Minga não reproduz a imagem de sensualidade estereotipada da meretriz que necessita de tal recurso para seduzir e atrair seus clientes. Assim, o estereótipo de prostituta é desconstruído na personagem, que se firma na narrativa como tal, mas não contém os atributos de sensualidade e feminilidade que a categoria geralmente apresenta. Minga, então, apresenta-se como um novo protótipo de meretriz instaurado no conto.

As escolhas lexicais contribuem para a constituição da imagem de mulheres marginalizadas pela escolha de seu modo de vida, bem como para a construção da imagem do feminino subversivo, com comportamentos que fogem do considerado padrão para a mulher do século XX, voltada à maternidade, ao casamento, e à vida privada do lar, necessários para a subsistência numa sociedade tradicional. As escolhas léxicas giram em torno do universo feminino, mas dão às personagens as características de força e resistência necessárias numa sociedade que as rejeita.

\section{REFERÊNCIAS}

AMOSSY, R.; HERSCHBERG PIERROT, A. Estereotipos y chichés. Buenos Aires: Eudeba, 2010.

BEAUVOIR, S. O segundo sexo: 1 - fatos e mitos. Tradução de Sérgio Milliet. 4. ed. São Paulo: Difusão Europeia do Livro, 1970.

O segundo sexo: 2 - a experiência vivida. Tradução de Sérgio Milliet. 2. ed. São Paulo: Difusão Europeia do Livro, 1967.

BOURDIEU, P. A dominação masculina. Tradução de Maria Helena Kühner. 3. ed. Rio de Janeiro: Bertrand Brasil, 2003.

BRITTO, C. C. "Sou Paranaíba pra cá": literatura e sociedade em Cora Coralina. 2006. 190 f. Dissertação (Mestrado em Sociologia) - Faculdade de Ciências Humanas e Filosofia, Universidade Federal de Goiás, Goiânia, 2006.

CAMARA JUNIOR, M. Contribuição à estilística portuguesa. 3. ed. Rio de Janeiro: Ao Livro Técnico, 1978.

Charaudeau, P.; MAIngueneaU, D. Dicionário de Análise do Discurso. São Paulo: Contexto, 2004. 
CORALINA, C. Estórias da casa velha da ponte. 13. ed. São Paulo: Global, 2006.

CUNHA, C.; CINTRA, L. F. L. Nova gramática do português contemporâneo. 3. ed. Rio de Janeiro: Nova Fronteira, 2001.

DAMATTA, R. A casa e a rua: espaço, cidadania, mulher e morte no Brasil. Rio de Janeiro: Rocco, 1985.

DENÓFRIO, D. F. (Org.). Lavra dos Goyases III - Leodegária de Jesus. Goiânia: Cânone Editorial, 2001.

FERREIRA, A. B. H. Dicionário da língua portuguesa. 5. ed. Curitiba: Positivo, 2010.

GARCIA, O. M. Comunicação em prosa moderna: aprenda a escrever, aprendendo a pensar. 25. ed. Rio de Janeiro: Editora FGV, 2006.

GASPAR, D. M. Garotas de programa. Prostituição em Copacabana e identidade social. 2. ed. Rio de Janeiro: Jorge Zahar Editor, 1985.

HOUAISS, A.; VILLAR, M. S. Dicionário Houaiss da língua portuguesa. Rio de Janeiro: Objetiva, 2001.

LYSARDO-DIAS, D. A construção e a desconstrução de estereótipos pela publicidade brasileira. Stockholm Review of Latin American Estudies, n. 2, p. 25-35, set. 2007.

MALUF, M.; MOTT, M. L. Recônditos do mundo feminino. In: NOVAIS, F. A. (Coord.); SEVCENKO, N. (Org.). História da vida privada no Brasil: República: da Belle Époque à Era do Rádio. v. 3. São Paulo: Companhia das Letras, 1998. p. 367-421.

MARTINS, N. S. Introdução à Estilística: a Expressividade na Língua Portuguesa. 4. ed. São Paulo: Editora da Universidade de São Paulo, 2012.

POSSENTI, S. Discurso, estilo e subjetividade. 2. ed. São Paulo: Martins Fontes, 2001.

RIFFATERRE, M. Estilística estrutural. Tradução de Anne Arnichand e Álvaro Lorencini. São Paulo: Cultrix, 1973.

STANGOR, C. Conceptualizing stereotypes and prejudice. In: (Ed.). Stereotypes and prejudice: essential readings. Philadelphia, Pa.: Psychology Press, 2000.

Recebido em: 30/08/2017

Aprovado em: 19/02/2018 